\title{
Collagen immunoassay as a method to optimise surface functionalisation
}

\section{Authors}

Gil Stynes *

George Kiroff

Wayne Morrison

Mark Kirkland

Dr. G.D. Stynes

Barwon Biomedical Research, University Hospital Geelong, Geelong 3220, Victoria, Australia.

Department of Surgery, St Vincent's Hospital Melbourne, University of Melbourne, Fitzroy 3065, Victoria, Australia.

Commonwealth Scientific and Industrial Research Organisation (CSIRO), Clayton 3168, Victoria, Australia.

Institute for Frontier Materials, Deakin University, Waurn Ponds 3218, Victoria, Australia gstynes@gmail.com

Assoc. Prof. G.K. Kiroff

Barwon Biomedical Research, University Hospital Geelong, Geelong 3220, Victoria, Australia.

Department of Surgery, The Queen Elizabeth Hospital, The University of Adelaide, Woodville 5011, South Australia, Australia. 
Prof. W.A. Morrison

Department of Surgery, St Vincent's Hospital Melbourne, University of Melbourne, Fitzroy 3065, Victoria, Australia.

Assoc. Prof. M.A. Kirkland

Institute for Frontier Materials, Deakin University, Waurn Ponds 3218, Victoria, Australia

Abstract. Traditional methods of assessing surface functionalisation, including spectroscopy and chemical labelling, often involve significant error and conjecture about bonds. Proteins that improve cell attachment have specific pKa's and optimum binding requirements that may differ from the conditions required for chemical labelling. The utility of collagen ELISA to optimise acetaldehyde glow discharge polymerisation reactor parameters was tested. Accurate stepwise increases in collagen conjugation strength were demonstrated by incubating specimens in $8 \mathrm{M}$ urea for 5 - 8 days followed by ELISA to test for residual surface collagen. Surface modifications also were assessed by XPS. The results suggest that ELISA after bondstressing with urea may suffice for optimising surface functionalisation and that traditional methods of analysis may be superfluous if protein conjugation is the aim of functionalisation.

\section{Introduction}

The type of protein and surface chemistry affects conjugation of proteins to materials ${ }^{1}$. Key questions about protein conjugation include the chemical nature of bonds (e.g. covalent vs. electrostatic), longevity, and the degree of retained protein function. Surface analysis is important for the interpretation of surface interactions ${ }^{2}$. However, the materials literature is replete with insufficient and inappropriate surface analyses and therefore questionable interpretations of biological responses ${ }^{3}$. 
Non-specific binding of proteins may be problematic because of competitive reduction of attachment of other proteins, such as fibronectin ${ }^{4}$. For example, adsorbed glycosaminoglycans have been implicated in titanium tooth implant failure ${ }^{5}$. The generation of reactive surface chemistries (functionalisation) transforms inert surfaces into biologically active surfaces ${ }^{6-8}$, thereby enhancing biointerfacial interactions ${ }^{9,10}$. Glow discharge polymerisation is a fast, clean, and safe method for surface functionalisation. It is applicable to a variety of substrates, is customisable via a variety of linkers ${ }^{11-15}$, and has been used to conjugate proteins to materials ${ }^{16,17}$. Acetaldehyde glow discharge polymerisation (Aapp) has been extensively investigated ${ }^{18-23}$; to attach albumin and other proteins to fluorinated ethylene propylene substrate ${ }^{18,24}$, to attach hyaluronan derivatives to metal surfaces ${ }^{25}$, and to attach collagen 1 to implantable contact lenses ${ }^{26,27}$. Aapp-based immobilisation of proteins has been described ${ }^{24}$ as a two-step process involving coupling protein amino groups to carbonyl groups of the deposited aldehyde layer, forming imines $(-\mathrm{CH}=\mathrm{N}-)$; followed by reduction of imines to stable amines (-CH2-NH-) by the addition of a reducing agent, such as sodium cyanoborohydride.

\section{Acetaldehyde $\mathrm{CH}_{3} \mathrm{CHO}$}

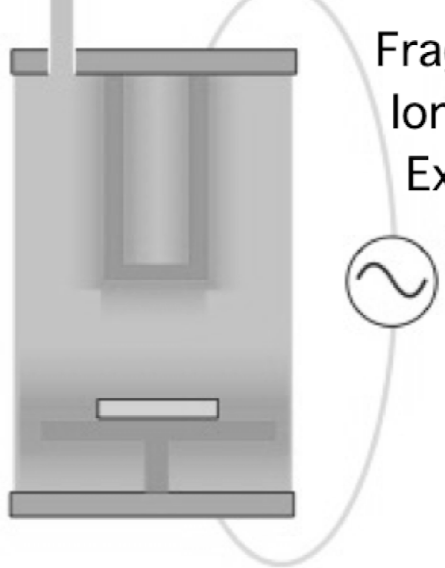

Fragmentation Ionisation Excitation

Figure 1. Acetaldehyde glow discharge polymerisation (image courtesy of CSIRO, with permission). 


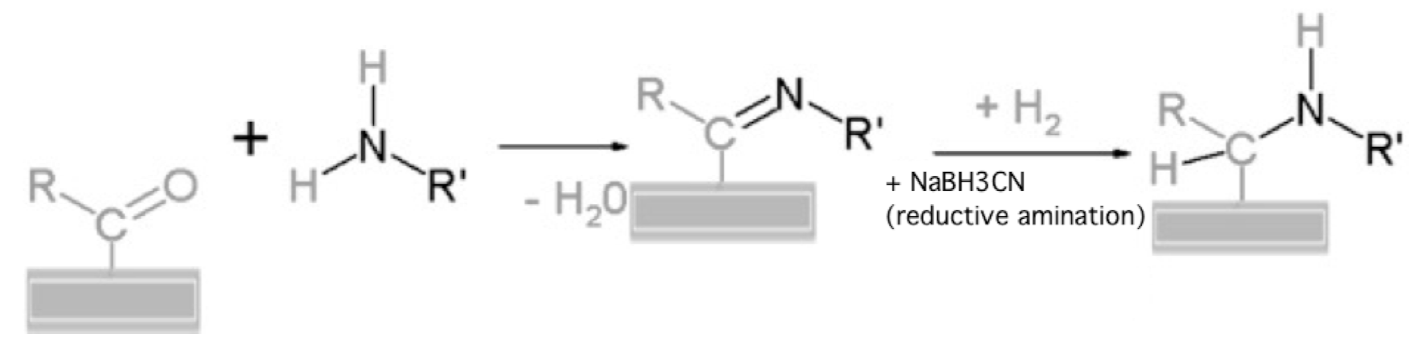

Figure 2. Covalent bonding of collagen to surface aldehyde groups. After deposition of surface aldehyde, collagen was added (represented by an amine group), forming an imine ($\mathrm{CH}=\mathrm{N}-)$ bond. The imine bond was reduced to a stable amine bond (-CH2-NH-) by the addition of sodium cyanoborohydride.

Occasionally the step of reductive amination has been omitted ${ }^{17,28}$ in the belief that "the imine bond formation is rapid and strong enough, allowing for a simple conjugation protocol” ${ }^{17}$ and on the premise that "the advantage (of omitting reductive amination) is that surface coupling is carried out in a single incubation step using only buffer and eliminates the possibility of surface contamination by reaction side products or reducing agents."

Analysis methods for chemical characterisation of surfaces include spectroscopy, water contact angle measurement, surface topography imaging, and colourimetric chemical derivativisation. Spectroscopic methods include X-ray photoelectron spectroscopy (XPS), surface plasmon resonance, time-of-flight secondary ion mass spectrometry (ToF-SIMS), Fourier transform infrared spectroscopy (FTIR), and metastable impact electron spectroscopy (MIES). Spectroscopic techniques can give useful information about the elemental composition, chemical state, and electronic state of surfaces. However, there are several disadvantages. Specimens need to be dehydrated, removing volatile gases (e.g. O2, CO) and water, which can change surface chemistry. Incomplete dehydration or incomplete vacuum in the analysis chamber can lead to water vapour and carbon dioxide artifacts ${ }^{29}$. Specimen 
preparation can take several hours and surface functional groups lose reactivity with time ${ }^{23}$. For example, the half-life of aldehyde groups is about 15 days in air and 12 days in PBS at $4^{\circ} \mathrm{C}^{30}$. Specimens typically are prepared in air; oxidation of surface functional groups on exposure to air significantly alters coatings ${ }^{23}$. Analysis areas range from $1-210000 \mu \mathrm{m}^{2}$ and rely on the assumption of surface homogeneity. Each analysis can take up to $30 \mathrm{~min}$, during which time surfaces can be changed by XPS itself, for example, degradation by X-rays. Additional problems are caused by the uncertainty of XPS peak intensity measurements, estimated at $10-15 \%{ }^{31}$. Finally, spectroscopic techniques like XPS involve significant conjecture about underlying chemical changes and reactivity ${ }^{23}$. For example, for the binding of streptavidin to an aldehyde-functionalised surface, XPS was unable to differentiate between covalent attachment and adsorption ${ }^{17}$.

Water contact angle measurement to assess surface functionalisation is prone to errors from contaminants ${ }^{3}$ and specimens require dehydration. A study investigating acetaldehyde glow discharge polymerisation (Aapp) excitation frequencies ${ }^{23}$ described water contact angles changing over $10^{\circ}$; differences in chemical reactivity may be difficult to elucidate over such ranges.

Atomic force microscopy (AFM) provides limited information about mechanical, van der Waals, capillary, electrostatic, and magnetic forces, and can be performed in air and liquid environments. However, like spectroscopic methods, it involves significant conjecture about underlying chemical changes and error ranges that make it difficult to differentiate adsorption from covalent and other bond types. For example, these problems prevented the determination of chemical changes from aldehyde reactions with silicon-containing surfaces ${ }^{32}$. 
Quartz crystal microbalancing (QCM) can be performed under vacuum, as well as in gas and liquid. It is very effective at determining changes in mass caused by the attachment of molecules, including proteins, to functionalised surfaces ${ }^{33-35}$. While enhancements to QCM, such as simultaneous SPR ${ }^{36}$, QCM with dissipation (QCM-D), and QCM with electrochemistry (EQCM) ${ }^{37-40}$ provide insights into chemical bonds and viscoelastic properties of conjugated layers, significant conjecture about bond types and conjugation strength is required.

Chemical derivatisation surface analysis is typically added to address the limitations of spectroscopic and other methods of surface analysis ${ }^{41}$. Derivativisation typically targets one specific aspect of surface chemical groups. For example, the reducing ability of aldehydes is utilised with potassium dichromate solution $^{42}$, the Schiff test ${ }^{43,44}$, Tollens' reagent ${ }^{45,46}$, Fehling's solution ${ }^{47}$, Benedict's solution ${ }^{48}$, and hydrazines in Wolff-Kishner reductions ${ }^{49-54}$. For proteins, all such methods are limited because conjugation is not simply a matter of labelling one aspect of surface reactivity, such as reducing ability; protein conjugation depends on several surface properties, including wettability, surface charge, and $\mathrm{pK}_{\mathrm{a}}{ }^{1}$. It was hypothesised that in situations where protein bonding is the aim of surface functionalisation, optimising functionalisation by optimising the resistance of conjugated protein to degradation in $8 \mathrm{M}$ urea may serve a twofold purpose: (1) it may be sufficient surface analysis and (2) it is essential for the interpretation of later biological responses. Further, it was proposed that collagen 1 enzyme-linked immunosorbent assay (ELISA) following incubation in $8 \mathrm{M}$ urea would be sufficiently sensitive to determine optimum glow discharge polymerisation reactor parameters (power, pressure, and exposure duration). 


\section{Experimental Section}

\section{$2.1 \quad$ Substrates}

A mixed macrodiol-based siloxane polyurethane, Elast-Eon ${ }^{\mathrm{TM}}{ }^{55,56}$ (Kindly gifted by Biomerics, Salt Lake City, UT 84119, United States), was laser cut into 5 mm x 5 mm x 2 $\mathrm{mm}$ blocks and into $5 \mathrm{~mm}$ and $8 \mathrm{~mm}$ diameter discs $(0.15 \mathrm{~mm}$ thickness $)$. The blocks were used for collagen-binding studies and the discs for XPS analysis. Each block was designed to stand on one $2 \mathrm{~mm}$ x $5 \mathrm{~mm}$ edge, thereby exposing five faces to chemical modification. To enable orientation, each disc was marked with an "L" on the opposite surface to the chemically treated side. Annealed 6 x $6 \mathrm{~mm} \mathrm{99.9 \%} \mathrm{pure} \mathrm{tantalum} \mathrm{squares} \mathrm{were} \mathrm{cut} \mathrm{from} 0.2$ $\mathrm{mm}$ thick foil and polished on both sides to $0.05 \mathrm{Ra}$ or better to standardise surface roughness (Goodfellow Ltd, Cambridge, United Kingdom; CFJ Metal Polishers, Oakleigh South, Australia; LaserXperts, Murwillumbah, Australia).

Elast-Eon ${ }^{\mathrm{TM}}$ blocks and discs were sonicated in purified water with $2 \%$ phosphate-free detergent (Tween 20 TM, Sigma-Aldrich) for two 20 min periods, sonicated in purified water for two 10 min periods, sonicated in ethanol (Sigma-Aldrich) for two 20 min periods, sonicated in purified water for a further $10 \mathrm{~min}$, and then dried in laminar-flow air at $20^{\circ} \mathrm{C}$. Tantalum squares were passivated by immersion in $45 \%$ nitric acid (Sigma-Aldrich) at $20^{\circ} \mathrm{C}$ for $12 \mathrm{~h}$, rinsed three times with purified water, and sonicated in purified water with Tween $20^{\mathrm{TM}}$ for two 20 min periods. Subsequently the squares were sonicated in purified water for three 10 min periods, sonicated in acetone (Sigma-Aldrich) for two 20 min periods, sonicated in purified water for $10 \mathrm{~min}$, and then dried in air at $37^{\circ} \mathrm{C}$.

\subsection{X-ray photoelectron spectroscopy}


X-ray photoelectron spectroscopy (XPS) was performed on treated and untreated specimens, described in detail elsewhere ${ }^{57}$. In brief, an AXIS-HSi spectrometer (Kratos Analytical Inc., Manchester, UK) with a monochromated Al Ka source at a power of $180 \mathrm{~W}(15 \mathrm{kV}$ x $12 \mathrm{~mA})$ was used, with a hemispherical analyser operating in the fixed analyser transmission mode using the standard aperture. The analysis area was $0.3 \mathrm{~mm} \times 0.7 \mathrm{~mm}$. The total pressure in the main vacuum chamber during analysis was less than 10 - 8 mbar. Survey spectra were acquired at a pass energy of $160 \mathrm{eV}$. Four significant fit components were used with the following tentative assignments ${ }^{58}: \mathrm{C} 1$ at $285.0 \mathrm{eV}(\mathrm{C}-\mathrm{C}, \mathrm{C}-\mathrm{H}), \mathrm{C} 2$ at $286.5-286.7 \mathrm{eV}$ (mainly C-O, possibly C-N), C3 at $288.0 \mathrm{eV}(\mathrm{O}-\mathrm{C}-\mathrm{O}, \mathrm{C}=\mathrm{O}, \mathrm{N}-\mathrm{C}=\mathrm{O})$ and $\mathrm{C} 4$ at approx. $289.5 \mathrm{eV}(\mathrm{O}-$ $\mathrm{C}=\mathrm{O}, \mathrm{N}-\mathrm{C}(\mathrm{O})-\mathrm{O})$.

\subsection{Glow discharge polymerisation, incubation in collagen solution, and reductive} amination

Aapp was performed in a custom-built reactor, described in detail elsewhere ${ }^{59}$. A commercial generator (Rochester N.Y. HPG-2 High Frequency Plasma Generator) powered the electrodes in the reactor, a chamber $35 \mathrm{~cm}$ in length and $17 \mathrm{~cm}$ in diameter. Samples were placed on the lower grounded electrode, a circular copper plate $9.5 \mathrm{~cm}$ in diameter. An 8-cm diameter copper disc acted as the upper electrode and the distance between the electrodes was $13 \mathrm{~cm}$. Monomer vapour was introduced into the chamber from liquid acetaldehyde contained in a round-bottom flask, kept on ice, via a stainless-steel line and manual valve for control of flow. The monomer liquid acetaldehyde $\left(\mathrm{C}_{2} \mathrm{H}_{4} \mathrm{O}\right)(>99.5 \%$, Sigma-Aldrich, Product \#402788) was of the best purity available and was used without further purification. Downstream of the reactor were a MKS Baratron pressure sensor and a pumping system using a Javac DDL 300 rotary high vacuum pump. Elast-Eon ${ }^{\mathrm{TM}}$ blocks were placed on the lower electrode and oriented such that each block rested on one narrow ( $2 \mathrm{~mm} \times 5 \mathrm{~mm}$ ) edge, exposing the two large sides $(5 \mathrm{~mm} \times 5 \mathrm{~mm})$ and three edges to the reactor environment. Tantalum squares 
were placed flat on the lower electrode and glow discharge polymerised on one side, turned over, and polymerised on the other side.

Care was taken to avoid oxygen contamination of specimens: Prior to glow discharge polymerisation initiation, the reactor was evacuated via large and fine gauge conduits to a base pressure below $0.001 \mathrm{mbar}$. This pressure was maintained for periods of $30-60 \mathrm{~min}$ to evaporate any volatile agents in the system. After closing the conduits, a maximum leak rate of $0.01 \mathrm{mbar} / \mathrm{minute}$ was permitted. Subsequently, monomer was introduced to the system for $90 \mathrm{~s}$, after which the vessel was evacuated again until a pressure of less than 0.001 mbar was obtained.

Following glow discharge polymerisation, specimens were removed and placed into collagen 1 solution (rat tail collagen, Sigma-Aldrich, Catalogue \#C7661) in PBS in wells in 96-well tissue culture plates, oriented such that 5 sides of the Elast-Eon ${ }^{\mathrm{TM}}$ blocks, both sides of the Elast-Eon ${ }^{\mathrm{TM}}$ discs, and both sides of the tantalum squares were exposed, for $2 \mathrm{~h}$ at $4^{\circ} \mathrm{C}$. Subsequently sodium cyanoborohydride (Sigma-Aldrich, reagent grade, 95\%, CAS Number 25895-60-7) was added to cause reductive amination ${ }^{60}$ in an excess concentration of 20 $\mathrm{mg} / \mathrm{ml}$. After incubating with sodium cyanoborohydride for $10 \mathrm{~h}$, specimens were washed with PBS five times.

\subsection{Optimisation of glow discharge polymerisation parameters} Previous research ${ }^{23}$ indicated that a frequency of $125 \mathrm{kHz}$ generated optimally hydrophilic and reactive acetaldehyde films. Hence, frequency was set at $125 \mathrm{kHz}$ and acetaldehyde was introduced with varying power, pressure, and time parameters. Broad ranges for these reactor parameters were based on previous research with Aapp ${ }^{18,23,24,61}$. For assessment of reactor variables, acetaldehyde monomer flow control and pump flow control valves were adjusted 
until a stable monomer pressure was obtained. Glow discharge polymerisation then was initiated. After deposition, the reactor was evacuated to under $0.001 \mathrm{mbar}$ before venting. To assess the optimum exposure time, chamber pressure was set to 0.3 mbar, power at $10 \mathrm{~W}$, frequency at $125 \mathrm{kHz}$, while time of exposure was varied between 0 and $120 \mathrm{~s}$. To assess the optimum power, chamber pressure was set at 0.3 mbar, exposure time was set at $60 \mathrm{~s}$, frequency at $125 \mathrm{kHz}$, while power was varied between 0 and $40 \mathrm{~W}$. To assess the optimum chamber pressure, exposure time was set at $60 \mathrm{~s}$, power at $10 \mathrm{~W}$, frequency at $125 \mathrm{kHz}$, while pressure was varied between 0 and 0.5 mbar. After Aapp, specimens were incubated with collagen $1(4 \mu \mathrm{g} / \mathrm{ml}$ in PBS), an excess concentration. Collagen 1 binding saturation had been previously noted from standard curves at a concentration $2 \mu \mathrm{g} / \mathrm{ml}$. To test the strength of bonding of collagen, specimens were incubated in $8 \mathrm{M}$ urea (Sigma-Aldrich, Product \#U5378) in purified water for 7 days, followed by ELISA to measure residual collagen. Three samples were used for each data point. $68 \%$ confidence interval error bars are included in all charts, representing one standard deviation either side of the mean.

\subsection{Collagen 1 ELISA}

The amount of collagen 1 on specimens was assessed by two-step ELISA. Prior to addition of the primary antibody, specimens were washed with $0.05 \%$ Tween $20^{\mathrm{TM}}$ in PBS (pH 7.4), washed twice with PBS, and then blocked with $1 \%$ bovine serum albumin (BSA) ('BovoStar', Bovogen, Product code $=$ BSAS $)$ in PBS $(\mathrm{pH}=7.4)$ for $2 \mathrm{~h}$. Mouse anti-collagen type 1 (Sigma-Aldrich, Product \#C2456) was used as primary antibody, diluted 1:160000 in 1\% BSA in PBS ( $\mathrm{pH}=7.4$ ) and incubated for $2 \mathrm{~h}$ at room temperature. This was followed by three washes as previously described. Anti-mouse IgG, HRP-linked antibody (Cell Signaling Technology, Product \#7076) was used as secondary antibody. It was diluted 1:8000 in 1\% BSA in PBS (pH 7.4) and incubated for $2 \mathrm{~h}$ at room temperature. This was followed by 3 washes as previously described. Specimens then were incubated in HRP substrate reagent 
(R\&D Systems, Catalog \#D999) for 25 min. Substrate reaction was stopped with $1 \mathrm{M}$ sulphuric acid. Colour change was measured in a Tecan Genios Pro microplate reader at a wavelength of $450 \mathrm{~nm}$. Three samples were used for each data point. $68 \%$ confidence interval error bars are included in all charts, representing one standard deviation either side of the mean.

\subsection{Urea elution of collagen 1}

For studies to assess bond strength (covalent vs. non-covalent bonding of collagen), reactor parameters of $20 \mathrm{~W}, 0.3 \mathrm{mbar}, 60 \mathrm{~s}$, and $125 \mathrm{kHz}$ were chosen, being within the optimal range for both Elast-Eon ${ }^{\mathrm{TM}}$ and tantalum (ascertained above). For specimens incubated with collagen 1, an excess concentration of $4 \mu \mathrm{g} / \mathrm{ml}$ was used. The four specimen types (untreated, Aapp treated, Aapp plus collagen treated, and Aapp plus collagen plus sodium cyanoborohydride) then were incubated in $8 \mathrm{M}$ urea for periods of up to 5 days (Elast-Eon ${ }^{\mathrm{TM}}$ ) and 8 days (tantalum). Two-step ELISA (as described above) was used to measure residual collagen 1 . Three samples were used for each data point. $68 \%$ confidence interval error bars are included in all charts using triplicate samples, representing one standard deviation either side of the mean.

\section{Results and Discussion}

\subsection{XPS results}

Surface contaminants $(\mathrm{C}, \mathrm{Si})$ were detected by XPS on untreated tantalum. Silicon contamination is a common problem encountered during XPS analysis, with many possible sources, including tapes, gloves, greases and oils, rinse water, solvents, cosmetics, shampoos, and atmospheric pollution ${ }^{62}$. The low level of detected silicon and the demonstrated ability to achieve covalent bonding of collagen suggested that surface silicon contamination was insignificant. The tantalum (Ta) signal was completely hidden by subsequent chemical layers. 
The large silicon $(\mathrm{Si})$ signal on untreated Elast-Eon ${ }^{\mathrm{TM}}$ was consistent with the incorporation of siloxane into polymer chains during the synthesis of Elast-Eon ${ }^{\mathrm{TM}}$; treatment with Aapp approximately halved the silicon ( $\mathrm{Si}$ ) signal. In addition, after glow discharge polymerisation treatment, the $\mathrm{C} 3$ peak increased from 0.006 to 0.040 on Elast-Eon ${ }^{\mathrm{TM}}$, consistent with the introduction of oxygen atoms in the form of $\mathrm{C}=\mathrm{O}$ groups in aldehydes. A similar increase is not seen on tantalum, probably due to the high level of surface oxides on untreated tantalum.

Untreated Elast-Eon ${ }^{\mathrm{TM}}$ presented a nitrogen peak at $400.2 \mathrm{eV}(0.048)$ due to $-\mathrm{N}-\mathrm{COO}$ and $\mathrm{C}=\mathrm{N}$ bonds ${ }^{63}$ (urethane nitrogen) ${ }^{64}$. The presence of a small amount of nitrogen on Aapptreated tantalum suggested contamination, possibly from amine monomers used previously in the glow discharge polymerisation reactor. A collagen-grafted layer on Aapp is suggested by an increase in nitrogen (on tantalum from 0.06 to 0.027 and on Elast-Eon ${ }^{\mathrm{TM}}$ from 0.017 to 0.024). The increase in nitrogen is proportionally larger than the increase seen in oxygen content on tantalum (from 0.152 to 0.170 ) and on Elast-Eon ${ }^{\mathrm{TM}}$ (from 0.245 to 0.26 ), suggesting that the increase in the $\mathrm{C} 2$ spectrum on tantalum (from 0.097 to 0.122 ) and on Elast-Eon $^{\mathrm{TM}}$ (from 0.129 to 0.146 ) was due to the introduction of nitrogen species in the collagen. The increase in the nitrogen peak following the addition of collagen is similar to results noted with grafting other nitrogen-containing moieties ${ }^{21,22}$.

Following reductive amination with sodium cyanoborohydride, there was a further increase in nitrogen levels on tantalum (from 0.027 to 0.072 ) and on Elast-Eon ${ }^{\mathrm{TM}}$ (from 0.024 to 0.053 ). There was an increase in oxygen content on tantalum (from 0.170 to 0.202 ) and on ElastEon $^{\mathrm{TM}}$ (from 0.26 to 0.286 ). In addition, there was an increase in the $\mathrm{C} 2(\mathrm{C}-\mathrm{O}, \mathrm{C}-\mathrm{N})$ spectrum on tantalum (from 0.122 to 0.154 ) and on Elast-Eon ${ }^{\mathrm{TM}}$ (from 0.146 to 0.151 ), possibly attributable to an increase in $\mathrm{C}-\mathrm{O}$ bonds. The significant increases in $\mathrm{O}, \mathrm{C} 2$, and $\mathrm{C} 3$ seen after reductive amination are consistent with increased levels of attached collagen. 
Collagen binding to Elast-Eon ${ }^{\mathrm{TM}}$ was optimal with pressure of 0.3 mbar, power in the range of $10-30 \mathrm{~W}$, and time in the range of $40-120 \mathrm{~s}$.
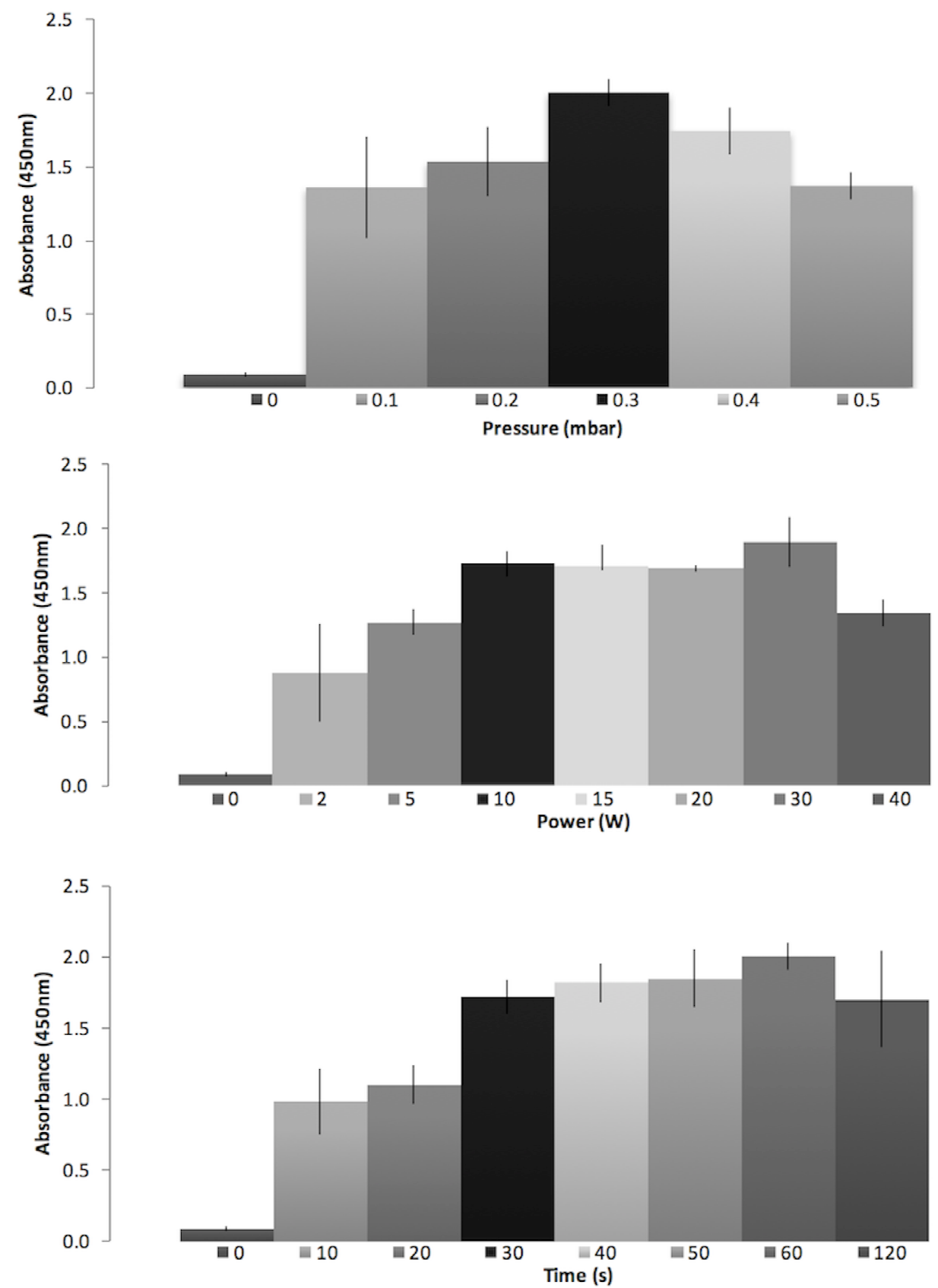

Figure 3. Optimisation of reactor parameters for Elast-Eon ${ }^{\mathrm{TM}}$.

Collagen binding to tantalum was optimal with pressure in the range of $0.1-0.5$ mbar, power in the range of $5-30 \mathrm{~W}$, and time in the range of $20-60 \mathrm{~s}$. 

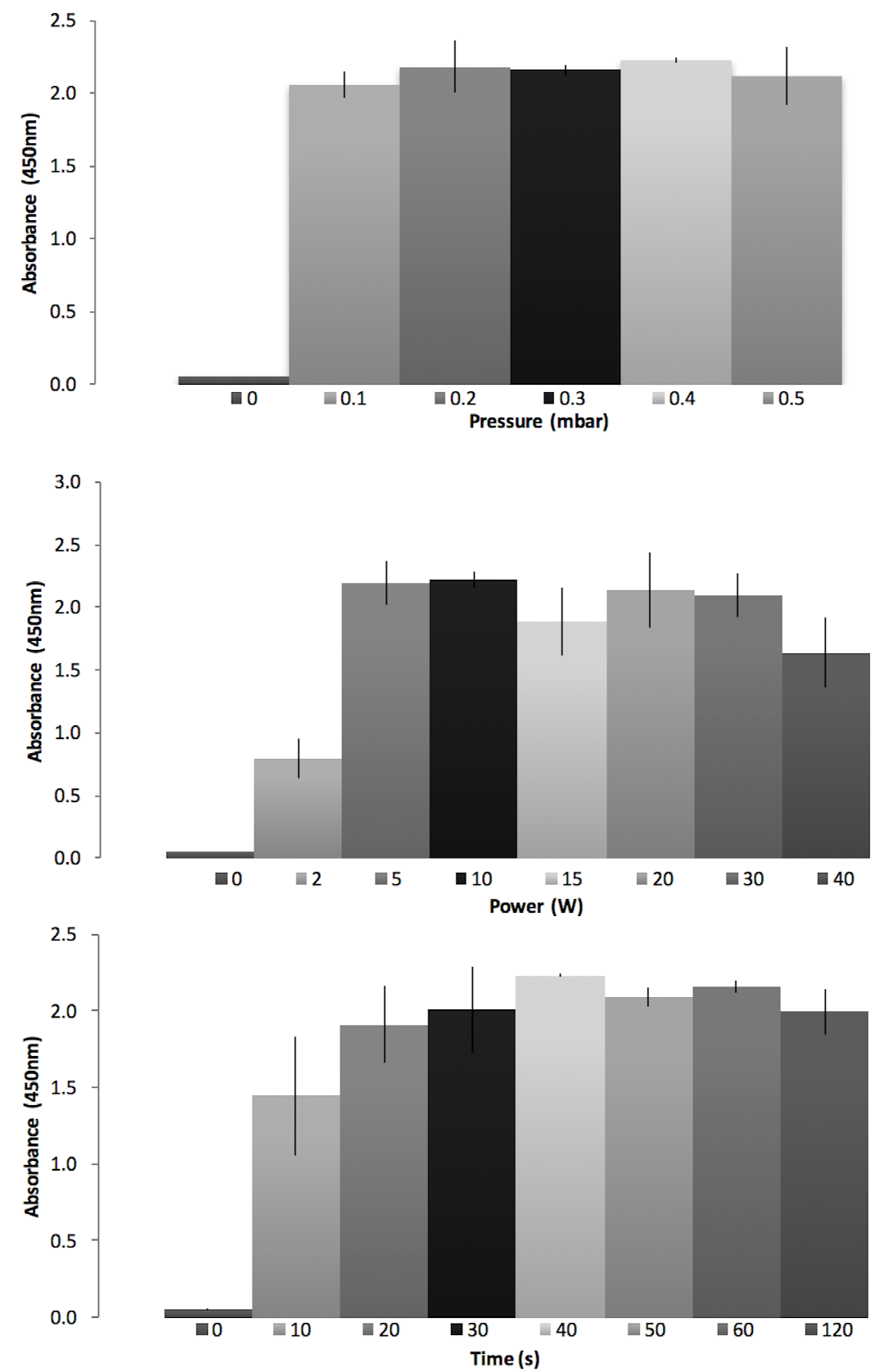

Figure 4. Optimisation of reactor parameters for tantalum.

\subsection{Urea elution of collagen 1 from Elast-Eon ${ }^{\mathrm{TM}}$ and tantalum}

After less than one day, on the Elast-Eon ${ }^{\mathrm{TM}}$ specimens, collagen was completely eluted from untreated samples, while 24\% was retained following Aapp, and 92\% retained following Aapp and reductive amination. After five days, residual collagen on Aapp specimens had plateaued at $12 \%$, while residual collagen on Aapp and sodium cyanoborohydride treated specimens was 39\%. Similar patterns were seen on tantalum: after two days, on untreated tantalum, collagen was retained at 66\%, which is more than that retained on Aapp tantalum 
(47\%), but less that retained on Aapp and sodium cyanoborohydride treated tantalum (94\%). After eight days, residual collagen on Aapp tantalum had plateaued at 9\%, a similar level to that retained on untreated tantalum, while residual collagen on specimens that included the reductive amination step was $24 \%$.

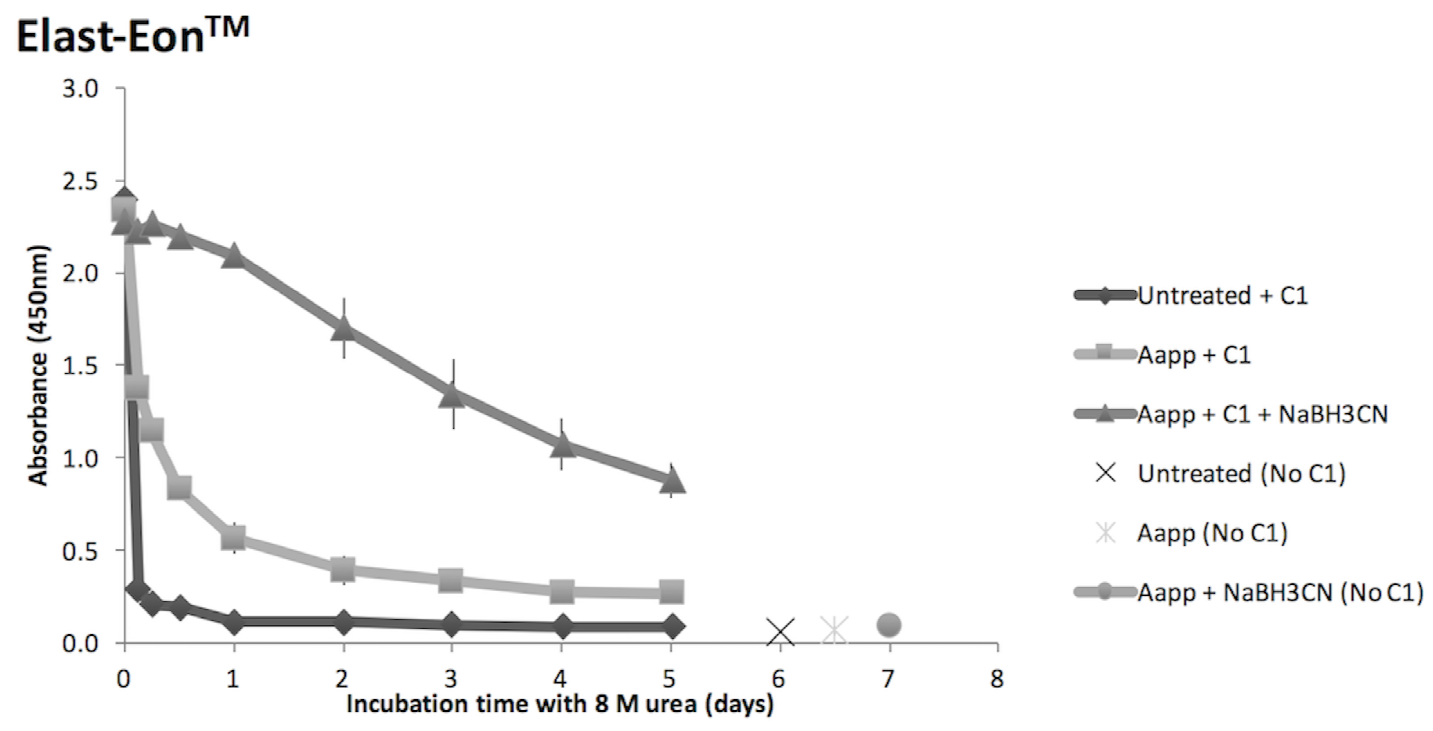

\section{Tantalum}

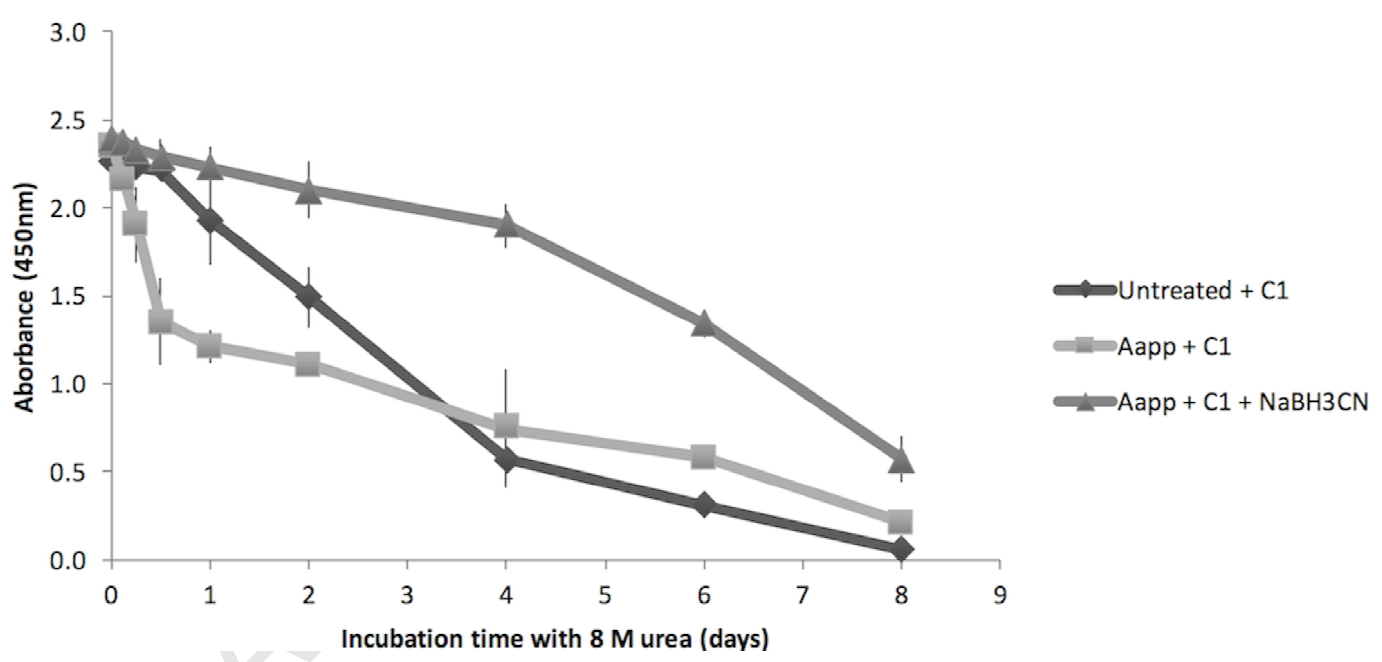

Figure 5. Urea elution of collagen 1 from Elast-Eon ${ }^{\mathrm{TM}}$ and tantlum.

On ELISA measurement, the absolute initial levels of conjugated collagen appeared similar for all specimens, regardless of treatment. This contrasts with the different levels of collagen measured by XPS on adsorbed, Aapp-treated, and Aapp-treated specimens subjected to reductive amination. The higher nitrogen, oxygen, $\mathrm{C} 2$, and $\mathrm{C} 3$ signals seen on tantalum and 
Elast-Eon ${ }^{\mathrm{TM}}$ treated with Aapp and sodium cyanoborohydride (reductive amination) may reflect a greater amount of collagen present on the surface and increased resistance to the effects of XPS preparation and analysis. Alternatively, the margin of error for XPS peak intensity measurements has been estimated at $10-15 \%{ }^{31}$; it is possible that XPS error ranges were responsible partly for signal differences between specimens with covalently bound collagen and those with adsorbed collagen.

While XPS results suggested the presence of surface collagen, it was unable to provide information about the residual activity of collagen or definitive information about bond types and strength. The determination of residual activity is important because conjugation of proteins causes protein denaturation ${ }^{65,66}$. The antibody used here for collagen ELISA is reactive with the native (helical) form of collagen 1 , is not reactive with denatured molecules, and is highly specific for collagen 1 , with no cross-reactivity with other collagen types ${ }^{67,68}$. Hence, derivativising conjugated collagen 1 with ELISA has the benefit of demonstrating residual protein activity.

Derivativisation techniques quantifying surface functional groups are typically performed immediately after conjugation using marker molecules. For example, colourimetric methods

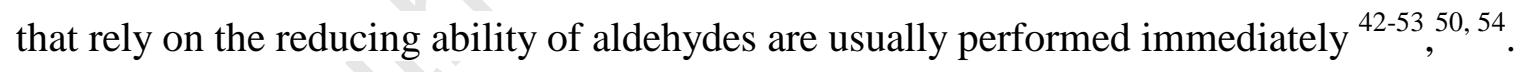
But such derivativisation techniques, being performed immediately and without a period stressing the conjugation bonds, give limited information. In addition, optimum protein conjugation may require different parameters compared to optimum marker molecule conjugation. Derivativising collagen 1 with ELISA after stressing bonds with $8 \mathrm{M}$ urea enabled optimisation of glow discharge polymerisation parameters and a clear demonstration of conjugation strength. 
Glow discharge polymerisation reactor parameters obtained via collagen 1 ELISA accorded with values obtained previously for Aapp using XPS, hyradrazine derivatisation, and contact angle measurements ${ }^{60,69}$. For tantalum, the upper limits of power, pressure, and exposure time were not explored: collagen binding was clearly optimal with the aforementioned parameters with statistically significant decreases in binding at $40 \mathrm{~W}$ and $120 \mathrm{~s}$ and a plateau for pressure between 0.1 and 0.5 mbar.

Stepwise increases in the strength of collagen conjugation were demonstrated with collagen ELISA. Urea elution studies showed significantly stronger binding of collagen 1 to Aapp specimens using optimised glow discharge polymerisation parameters. Reductive amination by the addition of sodium cyanoborohydride saw an additional increase in the strength of collagen conjugation. $8 \mathrm{M}$ urea is known to disrupt noncovalent bonds in proteins via incompletely elucidated mechanisms ${ }^{70,71}$. The significant increase in resistance to urea elution of collagen 1 observed after reductive amination appeared to be consistent with covalent bonding.

The initial amount of absolute bonding of collagen 1 was shown to be similar for adsorbed collagen, collagen on Aapp specimens (the intermediate step), and collagen on Aappspecimens followed by reductive amination (the step required for covalent bonding). The measurement of initial levels of collagen bonding may explain why some researchers choose to omit the final step (reductive amination) ${ }^{17,28}$ required for covalent bonding. The research reported herein demonstrated that initial absolute levels of attached proteins are similar, regardless of the type of conjugation. It is only by stressing the bonds in the conjugated protein that the strength of conjugation can be ascertained. Similarly, spectroscopic surface analysis methods that measure levels of nitrogen and other chemical changes as de facto 
measures for the presence of protein are likely to be testing absolute initial amounts attached to the material without necessarily demonstrating the type of bond to the material.

\section{Conclusion}

This research demonstrated the utility of protein ELISA for optimising glow discharge polymerisation parameters, demonstrating protein function and covalent bonding. The type of conjugation of proteins to materials and the degree of retained protein functionality are often assessed inadequately. Spectroscopic and colourimetric derivativisation techniques to assess surface chemical changes are problematic. Spectroscopic methods are complex, require vacuum, examine only small sections of substrate, have error ranges of $10-15 \%$, involve significant conjecture about chemical bond changes, and can adversely alter surfaces, for example, by X-radiation. Biological interactions occur in wet environments, in contrast to spectroscopic analyses, which require specimen dehydration. Cellular reactions to materials are improved by the attachment of proteins, all of which have specific pKa's and optimal binding conditions that may vary from the optimal binding conditions for chemical derivativisation markers. While ELISA showed that the absolute amount of collagen bound initially was similar for the three types of surface treatment, following incubation in $8 \mathrm{M}$ urea, collagen was found to be significantly more stable if covalently bound to substrate; the reductive amination step was critical. Many previously reported methods of assessing protein bonding measure initial protein attachment only, leading to incorrect conclusions about the nature of the conjugation and protein stability. Reliance on testing intermediate steps, such as surface functionalisation itself, can only give an approximate likelihood of covalent bonding and may provide undue reassurance about long-term protein stability. The results herein suggest that ELISA after bond-stressing with urea may suffice for optimising surface functionalisation and that traditional methods of analysis may be superfluous if protein conjugation is the aim of functionalisation. 


\section{ACKNOWLEDGEMENTS}

Dr. Thomas Gengenbach, CSIRO Melbourne, for extensive help with XPS analysis and interpretation.

Dr. Chris Easton, CSIRO Melbourne, for help with proof reading and editing.

Dr. Veronica Glattauer, for help with proof reading and editing.

Dr. Paul Pasic, CSIRO Melbourne, for help with glow discharge polymerisation equipment.

Dr. Cynthia Wong and Melinda Tursky, Barwon Biomedical Research, University Hospital Geelong Hospital, Victoria, Australia, for assistance with ELISA.

Dr. Cui'e Wen, Institute for Frontier Materials, Deakin University, Victoria, Australia, for providing samples of polished and cut tantalum.

CFJ Metal Polishers, Factory 1, 17 Edinburgh Street, Oakleigh South, VIC, 3167, for ultrapolishing tantalum.

This research was made possible by financial support from the Australian Commonwealth Government's Advanced Manufacturing Cooperative Research Centre (AMCRC) program, Cytomatrix Pty Ltd, the Victorian Centre for Advanced Materials Manufacturing, and Skin Meld Pty Ltd.

\section{Keywords}

collagen; functionalisation of polymers; immobilisation of molecules; glow discharge polymerisation; surface modification 


\section{Graphical abstract}

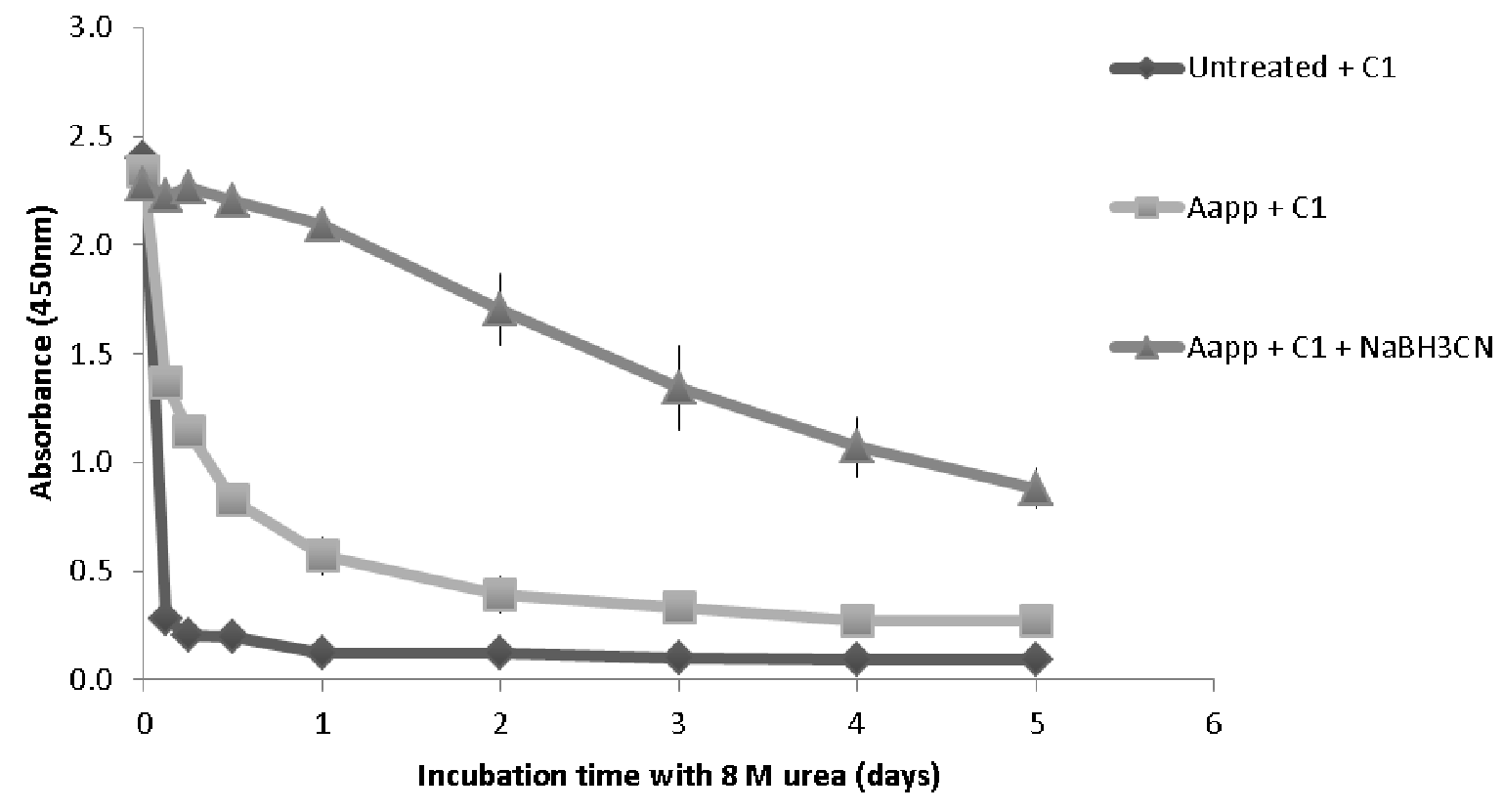

Traditional methods of assessing surface functionalisation, including spectroscopy and chemical labelling, often involve significant error and conjecture about bonds. Proteins that improve cell attachment have specific $\mathrm{pKa}$ 's and optimum binding requirements that may differ from the conditions required for chemical labelling. The utility of collagen ELISA to optimise acetaldehyde glow discharge polymerisation reactor parameters was tested. Accurate stepwise increases in collagen conjugation strength were demonstrated by incubating specimens in $8 \mathrm{M}$ urea for 5 - 8 days followed by ELISA to test for residual surface collagen. Surface modifications also were assessed by XPS. The results suggest that ELISA after bondstressing with urea may suffice for optimising surface functionalisation and that traditional methods of analysis may be superfluous if protein conjugation is the aim of functionalisation.

\section{Table of Contents}

2 EXPERIMENTAL SECTION 
2.3 GLOW DISCHARGE POLYMERISATION, INCUBATION IN COLLAGEN SOLUTION, AND REDUCTIVE AMINATION

2.4 OPTIMISATION OF GLOW DISCHARGE POLYMERISATION PARAMETERS

2.5 Collagen 1 Elisa

2.6 UREA ELUTION OF COLLAGEN 1

3 RESULTS AND DISCUSSION

3.1 XPS RESULTS

3.2 OPTIMISATION OF GLOW DISCHARGE POLYMERISATION PARAMETERS

3.3 UREA ELUTION OF COLLAGEN 1 FROM ELAST-EON ${ }^{\text {TM }}$ AND TANTALUM 16

$\begin{array}{llr}4 & \text { CONCLUSION } & 20\end{array}$

ACKNOWLEDGEMENTS

KEYWORDS

GRAPHICAL ABSTRACT

TABLE OF CONTENTS

\section{References}

1. J. D. Whittle, N. A. Bullett, R. D. Short, C. W. Douglas, A. P. Hollander and J. Davies, J Mater Chem, 2002, 12, 2726-2732.

2. B. Castner and B. D. Ratner, Surface Science, 2002, 500, 28-60.

3. P. Kingshott, G. Andersson, S. L. McArthur and H. J. Griesser, Current opinion in chemical biology, 2011, 15, 667-676.

4. M. Sun, J. Deng, Z. Tang, J. Wu, D. Li, H. Chen and C. Gao, Colloids and surfaces. B, Biointerfaces, 2014, 122C, 134-142.

5. J. I. Smedberg, C. B. Beck and G. Embery, Clin Oral Implants Res, 1993, 4, 137-143.

6. G. Gübitz, G. S. Nyanhongo and S. Walter, Biofunctionalization of Polymers and their Applications, Springer, Berlin, 2011.

7. A. de Mel, G. Jell, M. M. Stevens and A. M. Seifalian, Biomacromolecules., 2008, 9, 2969-2979.

8. T. Hanawa, J Periodontal Implant Sci, 2011, 41, 263-272.

9. W. R. Gombotz and A. S. Hoffman, Crc Critical Reviews in Biocompatibility, 1987, 4, $1-42$.

10. B. D. Ratner, A. Chilkoti and G. P. Lopez, Plasma deposition and treatment for biomaterial applications., Academic Press, San Diego, 1990.

11. H. Yasuda, J. Macromol. Sci.-Chem. A, 1976, 10, 383-420.

12. H. Yasuda, Radiat. Phys. Chem., 1977, 9, 805-817.

13. A. J. Ward and R. D. Short, Surface and Interface Analysis, 1994, 22, 477-482.

14. C. M. Chan, T. M. Ko and H. Hiraoka, Surface Science Reports, 1996, 24, 3-54.

15. A. J. Beck, S. Candan, S. R.D., A. Goodyear and N. S. J. Braithwaite, Journal of Physical Chemistry B., 2001, 105, 5730-5736.

16. K. S. Siow, L. Britcher, S. Kumar and H. J. Griesser, Plasma Process. Polym., 2006, 3, 392-418.

17. B. R. Coad, T. Scholz, K. Vasilev, J. D. Hayball, R. D. Short and H. J. Griesser, ACS applied materials \& interfaces, 2012, 4, 2455-2463. 
18. G. J. Beumer, R. C. Chatelier, H. A. W. St. John and H. J. Griesser, Surface topography and attachment factors in epithelial adhesion., Toronto, Canada, , 1996.

19. A. Chilkoti, B. D. Ratner and D. Briggs, A.C.S. Polym. Mater. Sci. Eng., 1990, 62, 135-139.

20. A. Chilkoti, B. D. Ratner and D. Briggs, Chem. Mater., 1991, 3, 51-61.

21. A. Hadjizadeh, J Biomed Mater Res B Appl Biomater., 2010, 94, 11-21.

22. K. M. McLean, G. Johnson, R. C. Chatelier, G. J. Beumer, J. G. Steele and H. J. Griesser, Colloids and surfaces. B, Biointerfaces, 2000, 18, 221-234.

23. X. Gong and H. J. Griesser, Plasmas and Polymers, 1997, 2, 261-276

24. U.S.A. Pat., WO2000029548, 2000.

25. B. Thierry, F. M. Winnik, Y. Merhi, H. J. Griesser and M. Tabrizian, Langmuir, 2008, 24, 11834-11841.

26. M. D. M. Evans, G. McFarland, S. Spencer, G. Johnson and K. M. McLean, J. Biomedical Material Research, 2001, 56, 461-468.

27. M. D. M. Evans, K. M. McLean, T. C. Hughes and D. F. Sweeney, Biomaterials, 2001, 22, 3319-3328.

28. K. R. Diener, S. N. Christo, S. S. Griesser, G. T. Sarvestani, K. Vasilev, H. J. Griesser and J. D. Hayball, Acta biomaterialia, 2012, 8, 99-107.

29. B. C. Smith, Fundamentals of Fourier Transform Infrared Spectroscopy, Second Edition, CRC Press, 2011.

30. M. Ghasemi, M. Minier, M. Tatoulian and F. Arefi-Khonsari, Langmuir, 2007, 23, 11554-11561.

31. S. Tougaard, Surf. Interface Anal., 1998, 26, 249-269.

32. C. Rogero, B. T. Chaffey, E. Mateo-Marti, J. M. Sobrado, B. R. Horrocks, A. Houlton, J. H. Lakey, C. Briones and J. A. Martin-Gago, J. Phys. Chem. C., 2008, 112, 93089314.

33. B. Becker and M. A. Cooper, J Mol Recognit, 2011, 24, 754-787.

34. K. A. Marx, Biomacromolecules, 2003, 4, 1099-1120.

35. C. I. Cheng, Y. P. Chang and Y. H. Chu, Chem Soc Rev, 2012, 41, 1947-1971.

36. J. Kim, S. Kim, T. Ohashi, H. Murumatsu, S. M. Chang and W. S. Kim, Bioprocess and biosystems engineering, 2010, 33, 39-45.

37. Y. Su, Q. Xie, C. Chen, Q. Zhang, M. Ma and S. Yao, Biotechnology progress, 2008, 24, 262-272.

38. R. Yu, M. Ma, L. Wang, Q. Xie, Z. Cao, X. Jiang and S. Yao, Biosens Bioelectron, 2009, 24, 1771-1776.

39. M. Gay-Martin, E. Diez-Arevalo, M. L. Rodriguez-Mendez and J. A. D. Saja, Sens. Actuators B., 2013, 185, 24-31.

40. S. Sigalov, M. D. Levi, G. Salitra and D. Aurbach, J. Electrochem. Commun., 2010, 12, 1718-1721.

41. J. Kim, D. Jung, Y. Park, Y. Kim, D. W. Moon and T. G. Lee, Appl. Surf. Sci., 2007, 253, 4112-4118.

42. J. B. Conant and C. O. Tongberg, J. Biol. Chem, 1930, 88, 701-708.

43. H. Schiff, Justus Liebigs Ann Chemie, 1866, 140, 92-137.

44. M. J. Hardonk and P. Van Duijn, J. Histochem. Cytochem., 1964, 12, 748-751.

45. W. E. Benet, J. Chem. Res., 2011, 35, 675-677.

46. K. Oshitna and B. Tollens, Ber. Dtsch. Chem. Ges., 1901, 34, 1425.

47. H. Fehling, Annalen der Chemie und Pharmacie, 1849, 72, 106-113.

48. S. R. Benedict, J. Biol. Chem, 1909, 5, 485-487.

49. O. L. Brady and G. V. Elsmie, Analyst., 1926, 51, 77-78.

50. S. K. Shannon and G. Barany, Journal of combinatorial chemistry, 2004, 6, 165-170. 
51. J. J. Cournoyer, T. Kshirsagar, P. P. Fantauzzi, G. M. Figliozzi, T. Makdessian and B. Yan, Journal of combinatorial chemistry, 2002, 4, 120-124.

52. J. Vázquez and F. Albericio, Tetrahedron Letters, 2001, 6691-6693.

53. G. E. Anthon and D. M. Barrett, Journal of agricultural and food chemistry, 2004, 52, 3749-3753.

54. S. K. Shannon and G. Barany, The Journal of organic chemistry, 2004, 69, 45864594.

55. P. A. Gunatillake, G. F. Meijs and R. Adhikari, Journal of Applied Polymer Science, 2000, 76, 2026-2040.

56. A. Simmons, J. Hyvarinen, R. A. Odell, D. J. Martin, P. A. Gunatillake, K. R. Noble and L. A. Poole-Warren, Biomaterials, 2004, 25, 4887-4900.

57. T. R. Gengenbach, R. C. Chatelier and H. J. Griesser, Surf. Interface Anal., 1996, 24, 271-281.

58. G. Beamson and D. Briggs, High Resolution XPS of Organic Polymers: The Scienta ESCA300 Database, John Wiley \& Sons, Ltd., New York, 1992.

59. H. J. Griesser, Vacuum, 1989, 39, 485-488.

60. H. J. Griesser, K. M. McLean and G. J. Beumer, Surface immobilisation of synthetic proteins via plasma polymer interlayers., 1999.

61. M. D. Evans, R. Z. Xie, M. Fabbri, M. C. Madigan, H. Chaouk, G. J. Beumer, G. F. Meijs, H. J. Griesser, J. G. Steele and D. F. Sweeney, Investigative ophthalmology \& visual science, 2000, 41, 1674-1680.

62. G. D. Davis, Surface and Interface Analysis, 1993, 20, 368-372.

63. F. Rossi, B. André, A. van Veen, P. E. Mijnarends, H. Schut, F. Labohm, H. Dunlop, M. P. Delplancke and K. Hubbard, J. Mater. Res., 1994, 9, 2440-2449.

64. A. Toth, I. Bertoti, M. Blazso, G. Banhegyi, A. Bognar and P. Szaplonczay, J Appl Polym Sci, 1994, 52, 1293-1307.

65. C. Tanford, Advances in protein chemistry, 1968, 23, 121-282.

66. C. Tanford, Advances in protein chemistry, 1970, 24, 1-95.

67. J. A. Werkmeister, D. E. Peters and J. A. Ramshaw, J Biomed Mater Res, 1989, 23, 273-283.

68. Sigma-Aldrich, Sigma-Aldrich, 2002.

69. G. J. Beumer, R. C. Chatelier, H. A. W. St. John and H. J. Griesser, unpublished work.

70. H. Frank and F. Franks, J Chem Phys., 1968, 48, 4746-4757.

71. J. M. Berg, J. L. Tymoczko and L. Stryer, Biochemistry, W.H. Freeman, New York, 2002.

HIDDEN TEXT FOUND PLEASE VERIFY IT FROM INPUT DOC FILE THEN DELETE

IT IF NOT REQUIRE::::::******************** </errorimage>

Table 1. XPS surface chemical compositions of tantalum specimens.

\begin{tabular}{|l|l|l|l|l|l|}
\hline & Untreated Ta & Ta & Ta & Ta & Peak Assignments \\
\hline
\end{tabular}




\begin{tabular}{|c|c|c|c|c|c|c|c|c|}
\hline & & + Aap & & $\begin{array}{l}+ \text { Aap } \\
+ \text { Coll }\end{array}$ & 1 & $\begin{array}{l}+ \text { Aapr } \\
+ \text { Coll } \\
+\mathrm{NaB}\end{array}$ & en 1 & \\
\hline & & Mean & Dev. & Mean & Dev. & Mean & Dev. & \\
\hline $\mathrm{O}$ & 1.224 & 0.152 & 0.004 & 0.17 & 0.004 & 0.202 & 0.009 & \\
\hline C (1) & 0.703 & 0.829 & 0.001 & 0.788 & 0 & 0.733 & 0.006 & C-C, C-H \\
\hline C (2) & 0.146 & 0.097 & 0.001 & 0.122 & 0.004 & 0.154 & 0.093 & $\mathrm{C}-\mathrm{O}, \mathrm{C}-\mathrm{N}$ \\
\hline C (3) & 0.052 & 0.049 & 0 & 0.063 & 0 & 0.091 & 0.004 & $\begin{array}{l}\mathrm{O}-\mathrm{C}-\mathrm{O}, \mathrm{C}=\mathrm{O}, \mathrm{N}- \\
\mathrm{C}=\mathrm{O}\end{array}$ \\
\hline C (4) & 0.099 & 0.025 & 0.003 & 0.026 & 0.004 & 0.021 & 0.002 & $\begin{array}{l}\mathrm{O}-\mathrm{C}=\mathrm{O}, \mathrm{N}-\mathrm{C}(\mathrm{O})- \\
\mathrm{O}\end{array}$ \\
\hline $\mathrm{N}$ & & 0.006 & 0.002 & 0.027 & 0.003 & 0.072 & 0.001 & \\
\hline $\mathrm{Si}$ & 0.051 & 0.005 & 0 & 0.005 & 0 & 0.008 & 0.002 & \\
\hline $\mathrm{Br}$ & & 0.004 & 0 & 0.004 & 0 & 0.003 & 0 & \\
\hline $\mathrm{Ta}$ & 0.383 & & & & & 0.001 & 0.001 & \\
\hline
\end{tabular}




\section{University Library}

\section{- M M N E R VA A gateway to Melbourne's research publications}

Minerva Access is the Institutional Repository of The University of Melbourne

Author/s:

Stynes, G;Kiroff, G;Morrison, W;Kirkland, M

Title:

Collagen immunoassay as a method to optimise surface functionalisation

Date:

2017-09-01

Citation:

Stynes, G., Kiroff, G., Morrison, W. \& Kirkland, M. (2017). Collagen immunoassay as a method to optimise surface functionalisation. PLASMA PROCESSES AND POLYMERS, 14 (9), https://doi.org/10.1002/ppap.201600213.

Persistent Link:

http://hdl.handle.net/11343/292423 